\title{
RANCANG BANGUN APLIKASI ANDROID UNTUK KONTROL LAMPU GEDUNG MENGGUNAKAN MEDIA BLUETOOTH BERBASIS ARDUINO UNO
}

\author{
ANDRI SUSANTO \& ISMAIL DARISMAN JAUHARI \\ Teknik Elektro Universitas Muhammadiyah Tangerang \\ Jl. Perintis Kemerdekaan I,No.33 Cikokol Kota Tangerang \\ Email:dj_ismail@ymail.com
}

\begin{abstract}
ABSTRAK
Dalam suatu gedung lampu adalah salah satu dari Bagian yang penting, untuk mempermudah mengendalikan lampu gedung digunakan perantara Bluetooth yang terintegrasi pada Android dan Arduino. Keseluruhan alat ini dibagi menjadi beberapa bagian yaitu terdiri atas handphone android, modul bluetooth HC-05, mikrokontroller arduino uno R3, modul relay, dan lampu. Alat ini bekerja saat Bluetooth handphone menyambungkan koneksi ke Bluetooth HC05, dari Bluetooth HC-05 kemudian ke mikrokontroler untuk memproses perintah, dari mikrokontroler kemudian ke modul relay yang bekerja sebagai pengganti saklar yang berfungsi untuk menghidupkan atau mematikan lampu yang di inginkan. Hasil penelitian yang menggunakan metode blackbox menunjukkan bahwa Aplikasi pada Android dapat berkomunikasi dengan arduino dengan jarak <12 meter. Aplikasi yang dibuat dapat melakukan 3 perintah yaitu dengan perintah tombol(ON/OFF), perintah suara(speech recognition), dan perintah countdown timer. Alat ini telah teruji dan bisa dijadikan media android smartphone light controller via koneksi Bluetooth tanpa harus menekan tombol lampu.
\end{abstract}

Kata Kunci: Arduino, Bluetooth HC-05, Android, Relay, Blackbox

\section{PENDAHULUAN}

Perkembangan teknologi saat ini mendorong manusia untuk terus berpikir kreatif, tidak hanya menggali penemuan-penemuan baru, tapi juga memaksimalkan kinerja teknologi yang ada untuk meringankan kerja manusia dalam kehidupan sehari-hari seperti pengendalian lampu gedung atau perangkat elektronik lainnya menggunakan mikrokontroler.

Di samping itu perkembangan ilmu pengetahuan dan teknologi tidak lepas dari gadget (smartphone) yang merupakan suatu software (perangkat lunak) yang digunakan pada perangkat mobile device, meliputi sistem operasi, middleware dan aplikasi inti. Kehadiran smartphone dengan sistem operasi android memberikan alternatif baru bagi para pengguna gadget. Pemanfaatan smartphone android sebagai alat komunikasi dan telepon cerdas telah banyak mengalami perkembangan saat ini, seperti sebagai alat pengendalian lampu penerangan rumah yang dipadukan dengan komponen mikrokontroler dan memanfaatkan fasilitas bluetooth yang ada pada smartphone android.

Berdasarkan hal tersebut, dengan adanya pengendalian lampu gedung dengan mikrokontroler dan keinginan memanfaatkan aplikasi android, maka penulis mengambil judul "Rancang Bangun Aplikasi Android Untuk Kontrol Lampu Gedung Menggunakan Media Bluetooth Berbasis Arduino Uno “.

\section{TINJAUAN PUSTAKA \\ 1. Android}

Dikutip dari (Akhir et al., 2015) android adalah sebuah sistem operasi Linux yang ditujukan untuk seluler, seperti smartphone dan komputer tablet. Android adalah open source jadi memberikan kesempatan kepada pengembang untuk menciptakan aplikasi mereka sendiri untuk digunakan di berbagai 
perangkat seluler dan tablet yang berbasis android. Salah satu kelebihan dari Android adalah ketersediaan aplikasi dari berbagai macam kategori: sosial, hiburan, permainan, dsb. Para developer bisa mengembangkan aplikasi sesuai dengan minat mereka masingmasing menggunakan Software Development Kit (SDK) yang telah didistribusikan oleh Google.

\section{MIT APP Inventor}

Menurut (Rumopa and Pembimbing, 2015) App Inventor adalah aplikasi web sumber terbuka yang awalnya dikembangkan oleh Google, dan saat ini dikelola oleh Massachusetts Institute of Technology (MIT). App Inventor memungkinkan pengguna baru untuk memprogram komputer untuk menciptakan aplikasi perangkat lunak bagi sistem operasi Android. App Inventor menggunakan antarmuka grafis, serupa dengan antarmuka pengguna pada Scratch dan Starlogo TNG, yang memungkinkan pengguna untuk mendrag-and-drop obyek visual untuk menciptakan aplikasi yang bisa dijalankan pada perangkat Android. Dalam menciptakan App Inventor.

\section{Arduino}

Menurut Syahwil (2013:80) arduino adalah kit elektronik atau papan rangkaian elektronik open source yang di dalamnya terdapat komponen utama, yaitu sebuah chip mikrokontroler dengan jenis AVR dari perusahaan Atmel. Mikrokontroler itu sendiri adalah chip atau IC (Integrated Circuit) yang bisa diprogram menggunakan komputer. Tujuan menanamkan program pada mikrokontroler adalah agar rangkaian elektronik dapat membaca input, memproses input tersebut dan kemudian menghasilkan output sesuai yang diinginkan.

Secara umum, Arduino terdiri dari dua bagian, yaitu:

a. Hardware berupa papan input/output (I/O) yang open source.

b. Software Arduino yang juga open source, meliputi software Arduino IDE untuk menulis program dan driver untuk koneksi dengan komputer.

\section{Modul Bluetooth $\mathrm{HC}$-05}

Menurut (Dinda Tisi Calista, 2013) bluetooth HC-05 merupakan module komunikasi nirkabel pada frekuensi $2.4 \mathrm{Ghz}$ dengan pilihan koneksi bisa sebagai slave ataupun master. Sangat mudah digunakan dengan mikrokontroller untuk membuat aplikasi wireless. Interface yang digunakan adalah serial RXD, TXD, VCC dan GND. Built in LED sebagai indikator koneksi bluetooth. Tegangan input bluetooth versi ini 3.6-6 V , jangan menghubungkan dengan sumber daya lebih dari $7 \mathrm{~V}$. Arus saat unpaired sekitar $30 \mathrm{~mA}$ dan saat paired sebesar $10 \mathrm{~mA}$. 4 pin $3.3 \mathrm{~V}$ dapat langsung dihubungkan ke berbagai macam mikrokotroller (khusus Arduino, 8051, 8535, AVR, PIC, ARM, MSP430, etc.). Jarak efektif jangkauan sebesar 10 meter, meskipun dapat mencapai lebih dari 10 meter, namun kualitas koneksi makin berkurang.

\section{Modul Relay}

Dikutip dari (Elektronika Teknik, 2017) relay adalah saklar (Switch) yang dioperasikan secara listrik dan merupakan komponen Electromechanical (Elektromekanikal) yang terdiri dari 2 bagian utama yakni Elektromagnet (Coil) dan Mekanikal (seperangkat Kontak Saklar/Switch).

\section{METODE PENELITIAN \\ 1. Tahapan Penelitian}

Tahapan penelitian adalah suatu bentuk cara berpikir yang dapat digunakan sebagai pendekatan dalam memecahkan suatu masalah. Biasanya pada suatu penelitian menggunakan pendekatan ilmiah dan memperlihatkan hubungan antar variable dalam proses analisisnya.

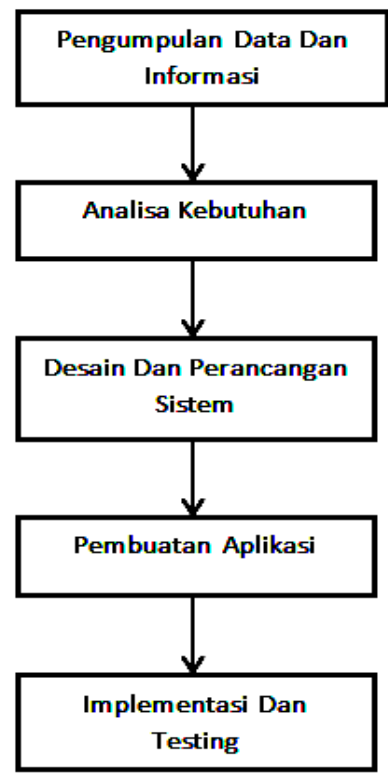

Gambar 3.1 Tahapan Penelitian 


\section{Analisis Kebutuhan}

Analisis kebutuhan sangat diperlukan guna menunjang penerapan sistem yang akan dibuat, agar sistem yang akan dibuat lebih terkonsep. Sejalan dengan sistem yang akan dibuat dibutuhkan perangkat teknologi yang mendukungnya perangkat itu meliputi perangkat keras Hardware dan perangkat lunak Software.

\section{1) Analisis Kebutuhan Perangkat Keras} Hardware

Perangkat keras yang digunakan dibagi menjadi 2 yaitu perangkat keras untuk pembuatan aplikasi dan perangkat keras untuk alat yang akan dibuat.

Spesifikasi perangkat keras yang digunakan untuk membuat aplikasi :

1. Laptop (ASUS, Pent T4400); dan

2. RAM 2 GB.

Perangkat keras yang digunakan untuk membuat alat:

1. Arduino uno;

2. Modul Bluetooth HC-05;

3. Modul Relay;

4. Lampu $220 \mathrm{~V}$;

5. Fitting Lampu;

6. Steker; dan

7. Kabel jumper untuk arduino dan kabel $1 \mathrm{~mm}$.

Sedangkan perangkat keras untuk penggunaan aplikasi ini adalah Handphone dengan sistem operasi Android 5.1 untuk menguji program.

\section{2) Analisis Kebutuhan Perangkat Lunak Software}

Perangkat lunak yang digunakan untuk membuat aplikasi ini adalah:

1. Sistem Operasi Windows;

2. Mozilla Firefox; dan

3. Arduino Ide 1.8.2.

\section{Diagram Blok Sistem}

Diagram blok merupakan gambaran dasar dari rangkaian sistem yang akan dirancang. Aplikasi pengontrol yang dirancang pada penulisan ini adalah Aplikasi android untuk kontrol lampu gedung, dimana aplikasi android yang dibuat digunakan sebagai input. Serta menggunakan media bluetooth sebagai komunikasi untuk mengirim perintah dari aplikasi android dan ditransfer melalui Bluetooth ke mikrokontroler yang dalam hal ini sebagai otak untuk mengaktifkan modul relay yang nantinya akan menghidupkan lampu.

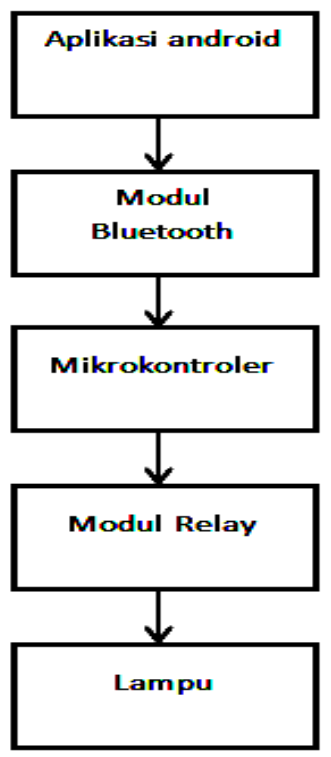

Gambar 3.2 Diagram blok system

\section{Perancangan Alat}

Dalam perancangan alat aplikasi android untuk kontrol lampu gedung menggunakan media bluetooth berbasis arduino ini meliputi perancangan software aplikasi android yang juga difungsikan sebagai input, perancangan hardware dan pembuatan program arduino.

1) Perancangan Software Aplikasi Android

Dalam perancangan software aplikasi android ini menggunakan tools App Inventor sebagai builder aplikasi. App Inventor adalah sebuah aplikasi builder untuk membuat aplikasi yang berjalan di sistem operasi android yang di sediakan oleh googlelabs. Untuk bisa masuk ke home App inventor di haruskan memiliki akun google terlebih dahulu. App inventor ini sedikit berbeda dengan App buider lain.

\section{2) Perancangan Perangkat Keras Hard- ware}

Perancangan perangkat keras hardware merupakan rancangan atau rangkaian dari alat yang digunakan untuk membangun prototipe pengendalian lampu gedung berbasis mikrokontroler arduino menggunakan smartphone android. 


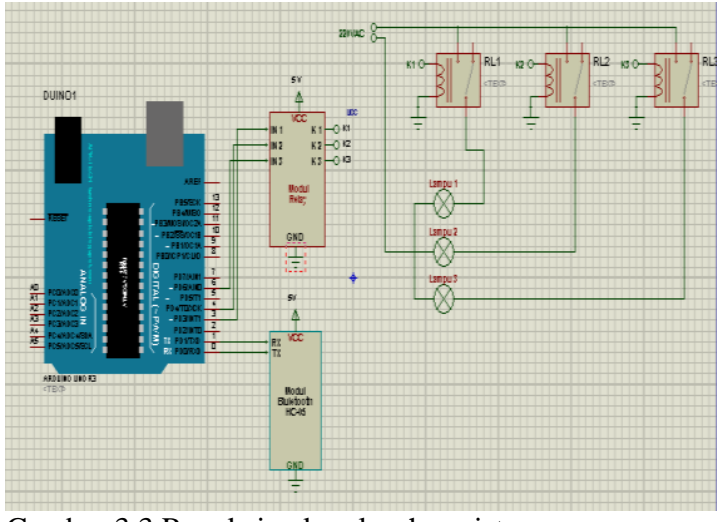

Gambar 3.3 Rangkaian keseluruhan sistem

\section{Pembuatan Program Arduino}

Mikrokontroller Arduino Uno R3 dapat bekerja dan memproses datagram yang dikirimkan dari Aplikasi android hanya jika didalamnya sudah dimasukkan listing program, program yang dimasukkan kedalam Arduino dibuat dan diupload ke Arduino menggunakan tools pemograman Arduino IDE. Fungsi program disini antara lain yaitu, menginisialisasi pin-pin mana saja yang akan menjadi output atau input, mengubah datagram yang dikirm dari Android menjadi perintah Logika " $H I G H$ " atau " $L O W$ " yang akan mengaktifkan atau mematikan relay dan output-output pendukung lainnya, serta menginisialisasi alamat IP bluetooth yang akan menjadi alamat tujuan pengiriman datagram dari Android. Dalam pemograman Arduino ini sendiri menggunakan bahasa pemograman $\mathrm{C}$.

\section{HASIL DAN PEMBAHASAN}

\section{Tujuan Pengujian}

Pengujian sistem ini memiliki tujuan untuk menguji kinerja serta hubungan antara perangkat keras dengan perangkat lunak sebagai program aplikasi system. Dengan pengujian ini dapat diketahui apakah alat dan aplikasi yang telah dirancang dapat bekerja sesuai dengan yang diinginkan atau tidak. Pengujian ini dilakukan pada perangkat keras dan perangkat lunak. Metode pengujian yang digunakan untuk menguji sistem ini menggunakan metode pengujian black box. Pengujian black box adalah pengujian aspek fundamental sistem tanpa memperhatikan struktur logika internal perangkat lunak. Metode ini digunakan untuk mengetahui apakah perangkat lunak berfungsi dengan benar.

\section{Implementasi Aplikasi \\ 1) Menu Login}

Pada menu Aplikasi terdapat 2 textbox untuk memasukan user name dan password, serta 1 push button untuk tombol submit, tampilan nya seperti gambar dibawah ini:

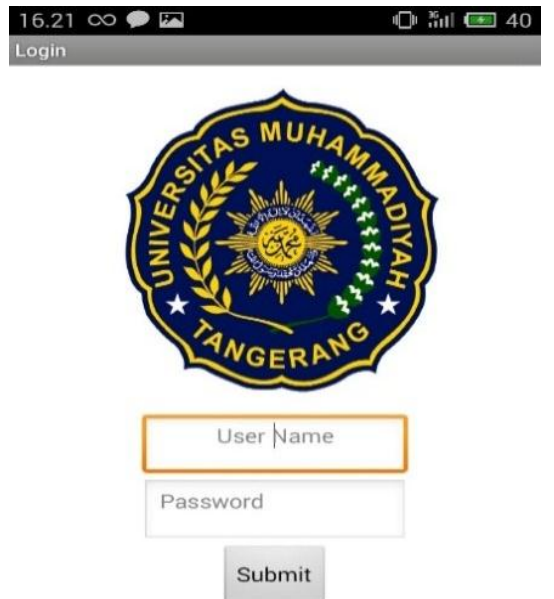

Gambar 4.1 Tampilan menu login

\section{2) Menu Utama}

Pada menu utama terdapat 3 tombol untuk memilih masuk ke perintah tombol, perintah suara, atau perintah countdown timer, tampilannya seperti gambar dibawah ini:

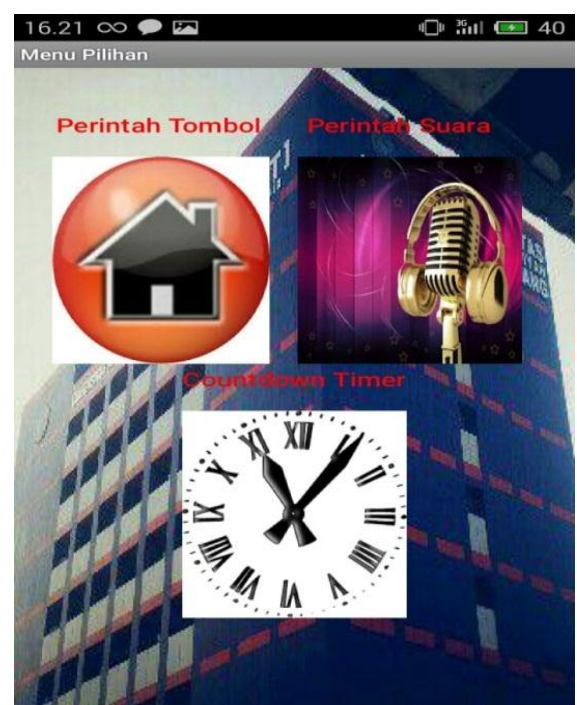

Gambar 4.2 Tampilan menu utama

\section{3) Menu Perintah Tombol}

Pada menu ini terdapat satu tombol untuk melihat listing device Bluetooth, dan tampilan indikator Bluetooth connected/not connected, serta dan 8 tombol push button untuk on/off lampu, tampilannya seperti gambar dibawah ini: 


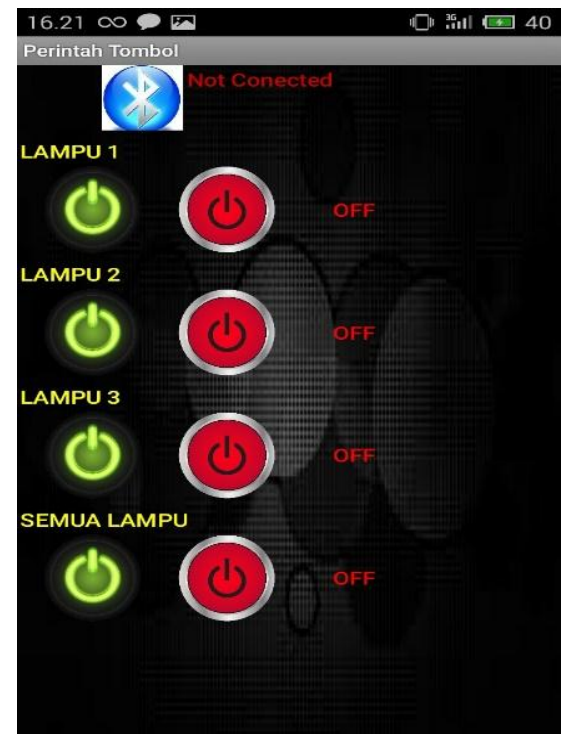

Gambar 4.3 Tampilan menu perintah tombol

\section{Menu Perintah Suara}

Pada menu ini terdapat satu tomnol untuk melihat listing device, dan satu tampilan indicator Bluetooth connected/ not connected, serta satu tombol speaker untuk mengucapkan perintah suara, tampilan nya seperti gambar dibawah ini:

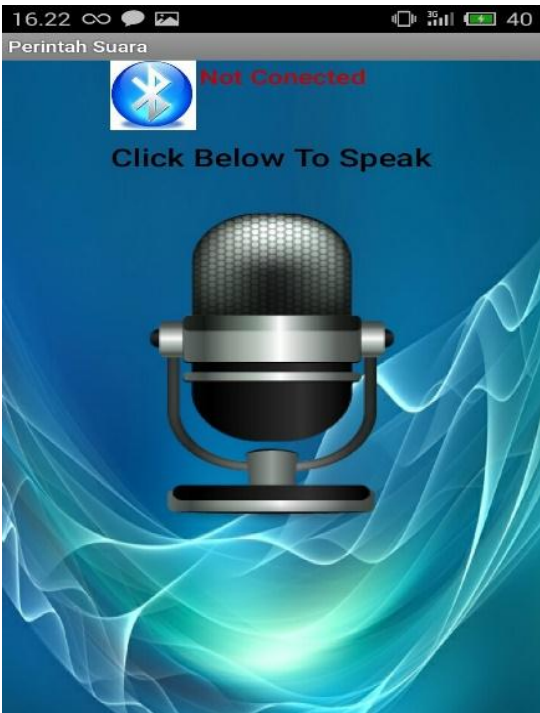

Gambar 4.4 Tampilan menu perintah suara

\section{Menu Perintah Countdown Timer}

Pada menu ini terdapat satu tomnol untuk melihat listing device, dan satu tampilan indicator Bluetooth connected/not connected, 3 tampilan indicator penghitung waktu, 3 tombol start, 3 tombol reset, dan 3 tombol untuk memasukan nilai setting timer, tampilan nya seperti pada gambar:

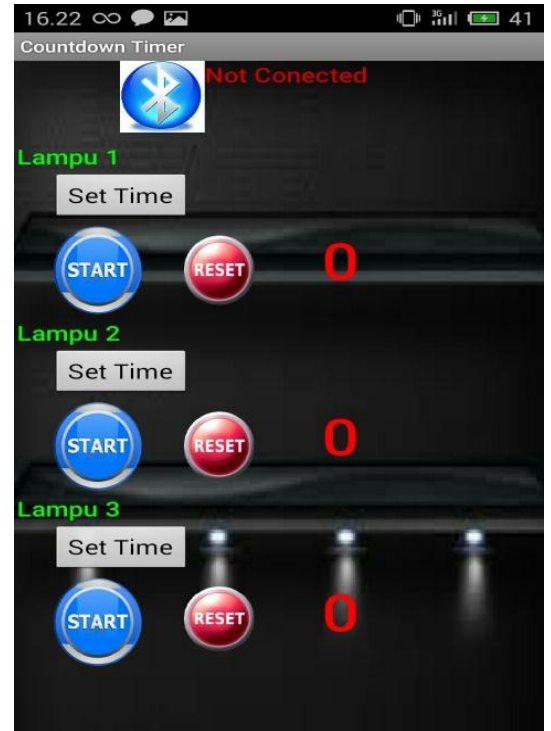

Gambar 4.5 Tampilan menu countdown timer

\section{Hasil Pengujian}

Berikut ini adalah hasil pengujian sistem menggunakan metode black box:

1) Pengujian Conection

Pengujian ini dilakukan untuk mengetahui apakah koneksi bluetooth dapat paired dan unpaired dengan menekan ikon bluetooth yang ada di aplikasi, hasil pengujian seperti tabel dibawah ini:

Tabel 4.1 Pengujian conection

\begin{tabular}{|c|c|c|c|c|}
\hline No & $\begin{array}{c}\text { Status } \\
\text { Bluetooth }\end{array}$ & Yang Diharapkan & Pengamatan & Kesimpulan \\
\hline 1 & Aktif & $\begin{array}{l}\text { Dapat menampilkan } \\
\text { nama buetooth }\end{array}$ & $\begin{array}{l}\text { Menampilkan } \\
\text { nama bluetooth }\end{array}$ & $\begin{array}{c}\text { []] Diterima } \\
\text { [] Ditolak }\end{array}$ \\
\hline 2 & $\begin{array}{l}\text { Terhubung/ } \\
\text { Connected }\end{array}$ & $\begin{array}{l}\text { Dapat menampilkan } \\
\text { pemberitahuan } \\
\text { "Connected" dan } \\
\text { dapat merubah } \\
\text { button "Connecf" } \\
\text { menjadi } \\
\text { "Disconnecf" }\end{array}$ & $\begin{array}{c}\text { Tampil } \\
\text { pemberitahyan } \\
\text { "Connected" } \\
\text { dan button } \\
\text { "Connecf" } \\
\text { berubah menjadi } \\
\text { "Disconnecf" }\end{array}$ & 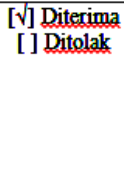 \\
\hline
\end{tabular}

\section{2) Pengujian Jarak Jangkauan Bluetooth}

Dalam pengujian jangkauan bluetooth ini dilakukan pada kondisi yang berbeda yaitu pada kondisi ada halangan seperti mendapat halangan dari tembok, dan pengujian tanpa ada halangan di ruang terbuka, hasil pengujian nya seperti pada tabel dibawah ini: 
Tabel 4.2 Hasil pengujian jarak jangkauan Bluetooth

\begin{tabular}{|c|c|c|c|}
\hline No & Jangkauan & Kondisi Ruangan & Kesimpulan \\
\hline \multirow[t]{2}{*}{1} & \multirow[t]{2}{*}{ 1-10 Meter } & Tanpa penghalang & $\begin{array}{c}\text { []] Diterima } \\
\text { [] Ditolak }\end{array}$ \\
\hline & & Ada halangan & $\begin{array}{c}{[\sqrt{ }] \text { Diterima }} \\
{[] \text { Ditolak }}\end{array}$ \\
\hline \multirow[t]{2}{*}{2} & \multirow[t]{2}{*}{12 Meter } & Tanpa halangan & $\begin{array}{c}\text { [1] Diterima } \\
\text { [] Ditolak }\end{array}$ \\
\hline & & Ada halangan & $\begin{array}{l}\text { [] Diterima } \\
\text { [v] Ditolak }\end{array}$ \\
\hline \multirow[t]{2}{*}{3} & \multirow[t]{2}{*}{ jarak $>15$ Meter } & Tanpa penghalang & $\begin{array}{l}\text { [] Diterima } \\
\text { [v] Ditolak }\end{array}$ \\
\hline & & Ada penghalang & $\begin{array}{l}\text { [] Diterima } \\
\text { [v] Ditolak }\end{array}$ \\
\hline
\end{tabular}

\section{3) Pengujian Via kendali ON/OFF Button}

Tabel 4.3 Pengujian via kendali on/off button

\begin{tabular}{|c|c|c|c|c|c|}
\hline No & $\begin{array}{c}\text { Button } \\
\text { Yang } \\
\text { Ditelean }\end{array}$ & $\begin{array}{l}\text { Status } \\
\text { Lampu }\end{array}$ & $\begin{array}{c}\text { Yang } \\
\text { diharapksas }\end{array}$ & Penganatan & Kesimpulan \\
\hline \multirow[t]{2}{*}{1} & \multirow[t]{2}{*}{$\begin{array}{c}\text { Lampy lon } \\
/ \\
\text { Lampu } 1 \text { off }\end{array}$} & $\begin{array}{l}\text { Lamph } \\
\text { merah } \\
\text { menxals }\end{array}$ & $\begin{array}{c}\text { Lampu } \\
\text { merah dapat } \\
\text { mati }\end{array}$ & $\begin{array}{c}\text { Lampu } \\
\text { merah mati }\end{array}$ & 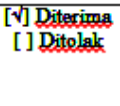 \\
\hline & & $\begin{array}{c}\text { Lampu } \\
\text { merah mati }\end{array}$ & $\begin{array}{c}\text { Lampu } \\
\text { merah danat } \\
\text { zeenxals }\end{array}$ & $\begin{array}{l}\text { Lamph } \\
\text { merah } \\
\text { menvala }\end{array}$ & $\begin{array}{c}\text { [V] Diterimos } \\
\text { [] Ditelak }\end{array}$ \\
\hline \multirow[t]{2}{*}{2} & \multirow[t]{2}{*}{$\begin{array}{c}\text { Lampu } 2 \\
\text { on/ Lampu } \\
2 \text { off }\end{array}$} & $\begin{array}{l}\text { Lampy } \\
\text { biru } \\
\text { menxala }\end{array}$ & $\begin{array}{l}\text { Lampu biru } \\
\text { danat mati }\end{array}$ & $\begin{array}{c}\text { Lampu biru } \\
\text { mati }\end{array}$ & 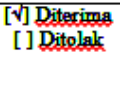 \\
\hline & & $\begin{array}{c}\text { Lampu } \\
\text { biru mati }\end{array}$ & $\begin{array}{l}\text { Lampu biru } \\
\text { danat } \\
\text { menxala }\end{array}$ & $\begin{array}{c}\text { Lampu biru } \\
\text { mensala }\end{array}$ & $\begin{array}{c}\text { [V] Diterimos } \\
\text { [] Ditslak }\end{array}$ \\
\hline \multirow[t]{2}{*}{3} & \multirow[t]{2}{*}{$\begin{array}{c}\text { Lampu } 3 \\
\text { on/ Lampu } \\
3 \text { off }\end{array}$} & $\begin{array}{l}\text { Laxpy } \\
\text { buning } \\
\text { menxala }\end{array}$ & $\begin{array}{c}\text { Lampu } \\
\text { kuning dangt } \\
\text { mati }\end{array}$ & $\begin{array}{c}\text { Lampu } \\
\text { buning mati }\end{array}$ & 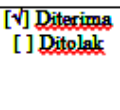 \\
\hline & & $\begin{array}{l}\text { Lamph } \\
\text { kaning } \\
\text { mati }\end{array}$ & $\begin{array}{c}\text { Lampu } \\
\text { kuning dangt } \\
\text { mensala }\end{array}$ & $\begin{array}{l}\text { Lampy } \\
\text { buning } \\
\text { mensalas }\end{array}$ & 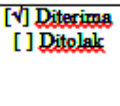 \\
\hline \multirow[t]{2}{*}{4} & \multirow[t]{2}{*}{$\begin{array}{c}\text { Semus } \\
\text { Lampu on } \\
\text { Sermus } \\
\text { Lampu off }\end{array}$} & $\begin{array}{l}\text { Sempus } \\
\text { lanpu } \\
\text { menxala }\end{array}$ & $\begin{array}{c}\text { Sernus } \\
\text { lampu dangt } \\
\text { mati }\end{array}$ & $\begin{array}{c}\text { Serfua } \\
\text { lampu mati }\end{array}$ & $\begin{array}{c}\text { [v] Diterimos } \\
\text { [ ] Ditelak }\end{array}$ \\
\hline & & $\begin{array}{c}\text { Sernus } \\
\text { lampu mati }\end{array}$ & $\begin{array}{c}\text { Semus } \\
\text { lampu danat } \\
\text { menxals }\end{array}$ & $\begin{array}{l}\text { Semus } \\
\text { lampu } \\
\text { menxals }\end{array}$ & $\begin{array}{c}\text { [v] Diterimos } \\
\text { [] Ditelak }\end{array}$ \\
\hline
\end{tabular}

4) Pengujian Via kendali Perintah Suara

Tabel 4.4 Pengujian via perintah suara

\begin{tabular}{|c|c|c|c|c|c|}
\hline No & $\begin{array}{l}\text { Perintah Yang } \\
\text { Diucankan }\end{array}$ & $\begin{array}{l}\text { Status } \\
\text { Lampu }\end{array}$ & $\begin{array}{c}\text { Yang } \\
\text { diharapkan }\end{array}$ & Pengamatan & Kesimpulan \\
\hline \multirow[t]{2}{*}{1} & \multirow[t]{2}{*}{ Merab on/off } & $\begin{array}{l}\text { Lampu } \\
\text { merah } \\
\text { menyala }\end{array}$ & $\begin{array}{l}\text { Lampu } \\
\text { merah dapat } \\
\text { mali }\end{array}$ & $\begin{array}{l}\text { Lampy } \\
\text { merah mati }\end{array}$ & $\begin{array}{l}\text { [v] Diterima } \\
\text { []Ditolalk }\end{array}$ \\
\hline & & $\begin{array}{c}\text { Lampu } \\
\text { merahmati }\end{array}$ & $\begin{array}{c}\text { Lampu } \\
\text { merah dapat } \\
\text { menxala }\end{array}$ & $\begin{array}{l}\text { Lampy } \\
\text { merah } \\
\text { menyala }\end{array}$ & $\begin{array}{l}{[\sqrt{2}] \text { Diterima }} \\
\text { []Ditolala }\end{array}$ \\
\hline \multirow[t]{2}{*}{2} & \multirow[t]{2}{*}{ Bing on/off } & $\begin{array}{l}\text { Lampon biru } \\
\text { meaxala }\end{array}$ & $\begin{array}{l}\text { Lampu binu } \\
\text { dapat mati }\end{array}$ & $\begin{array}{c}\text { Lampu biru } \\
\text { mati }\end{array}$ & $\begin{array}{c}\text { [V]Diterima } \\
\text { []Ditolala }\end{array}$ \\
\hline & & $\begin{array}{l}\text { Lampon biou } \\
\text { mati }\end{array}$ & $\begin{array}{l}\text { Lampu bicu } \\
\text { dapat } \\
\text { menyala }\end{array}$ & $\begin{array}{l}\text { Lampu bitu } \\
\text { menyala }\end{array}$ & $\begin{array}{l}{[\sqrt{ }] \text { Diterima }} \\
\text { []Ditolala }\end{array}$ \\
\hline \multirow[t]{2}{*}{3} & \multirow[t]{2}{*}{ Kuning on/off } & $\begin{array}{l}\text { Lampor } \\
\text { kunipg } \\
\text { menvala }\end{array}$ & $\begin{array}{c}\text { Lampd } \\
\text { kuning danat } \\
\text { mati }\end{array}$ & $\begin{array}{c}\text { Lampu } \\
\text { hunimg mati }\end{array}$ & $\begin{array}{c}{[\sqrt{2}] \text { Diterima }} \\
\text { []Ditolak }\end{array}$ \\
\hline & & $\begin{array}{l}\text { Lampuy } \\
\text { huning mati }\end{array}$ & $\begin{array}{c}\text { Lampu } \\
\text { huning dapat } \\
\text { menxala }\end{array}$ & $\begin{array}{l}\text { Lampu } \\
\text { kuning } \\
\text { menxala }\end{array}$ & $\begin{array}{c}\sqrt{ }] \text { Diterima } \\
\text { []Ditolak }\end{array}$ \\
\hline \multirow[t]{2}{*}{4} & \multirow[t]{2}{*}{ Semua on/off } & $\begin{array}{l}\text { Semua } \\
\text { lampu } \\
\text { menyala }\end{array}$ & $\begin{array}{c}\text { Semua } \\
\text { lampudanat } \\
\text { mati }\end{array}$ & $\begin{array}{c}\text { Semua } \\
\text { lampumati }\end{array}$ & $\begin{array}{c}{[\sqrt{2}] \text { Diterima }} \\
\text { []Ditolala }\end{array}$ \\
\hline & & $\begin{array}{c}\text { Semua } \\
\text { lampunatio }\end{array}$ & $\begin{array}{c}\text { Semua } \\
\text { lampudapat } \\
\text { menyals }\end{array}$ & $\begin{array}{l}\text { Semua } \\
\text { lampu } \\
\text { menyala }\end{array}$ & $\begin{array}{l}{[\sqrt{2} \text { Diterima }} \\
\text { []Ditolala }\end{array}$ \\
\hline
\end{tabular}

5) Pengujian Via Countown Timer

Tabel 4.5 Pengujian via countdown timer

\begin{tabular}{|c|c|c|c|c|}
\hline No & Yang dilakukan & $\begin{array}{c}\text { Yang } \\
\text { diharapkan }\end{array}$ & Pengamatan & Kesimpulan \\
\hline 1 & $\begin{array}{l}\text { Mensetting nilai } \\
\text { waktu timer } \\
\text { sesuai dengan } \\
\text { keinginan dan } \\
\text { menekan tombol } \\
\text { start }\end{array}$ & $\begin{array}{l}\text { Tampilan timer } \\
\text { berubah sesuai } \\
\text { setingan yang } \\
\text { diinginkan dan } \\
\text { lampu menyala } \\
\text { yang lama nya } \\
\text { sesuai dengan } \\
\text { setingan timer }\end{array}$ & $\begin{array}{c}\text { Tampilan } \\
\text { timer dapat } \\
\text { berubah sesuai } \\
\text { setingan yang } \\
\text { diinginkan dan } \\
\text { lampu dapat } \\
\text { menyala yang } \\
\text { lama nya sesuai } \\
\text { dengan } \\
\text { setingan timer }\end{array}$ & $\begin{array}{l}\text { [ } \sqrt{\text { Diterima }} \\
\text { [] Ditolak }\end{array}$ \\
\hline 2 & $\begin{array}{l}\text { Menekan } \\
\text { tombol reset }\end{array}$ & $\begin{array}{c}\text { Lampu mati dan } \\
\text { nilai tampilan } \\
\text { timer menjadi } \\
\text { nol }\end{array}$ & $\begin{array}{l}\text { Lampu dapat } \\
\text { mati dan nilai } \\
\text { tampilan timer } \\
\text { menjadi nol }\end{array}$ & 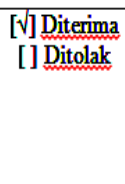 \\
\hline
\end{tabular}

\section{Pengukuran Tegangan Relay}

Pada pengukuran tegangan relay dilakukan pada saat relay aktif dan pada saat relay tidak aktif, hasil pengujian nya seperti pada tabel dibawah ini: 
Tabel 4.6 Pengukuran tegangan relay

\begin{tabular}{|l|l|l|}
\hline \multirow{4}{*}{$\begin{array}{l}\text { Vcc }=5 \\
\mathrm{~V}\end{array}$} & Keadaan & $\begin{array}{l}\text { Tegangan } \\
\text { (Volt) }\end{array}$ \\
\cline { 2 - 3 } & Aktif & $4.8 \mathrm{~V}$ \\
\cline { 2 - 3 } & Tidak aktif & $0 \mathrm{~V}$ \\
\hline
\end{tabular}

\section{Pembahasan}

Dari implementasi aplikasi dan tabel hasil pengujian diatas diketahui bahwa aplikasi dapat di install dan dijalankan di smartphone android untuk melakukan inputan kepada mikrokontroler melalui media bluetooth, selain itu smartphone android dapat melakukan 3 pengontrolan:

1. Perintah button on/off ketika kita tekan tombol warna hijau maka lampu akan on dan ketika ditekan tombol warna merah makan lampu akan off;

2. Perintah suara ketika kita tekan tombol speaker dan mengucapkan perintah sesuai dengan yang ada di sketch arduino maka lampu akan on/off sesuai dengan perintah tersebut; dan

3. Perintah countdown timer pada perintah ini kita bisa menseting waktu sesuai keinginan kita, tombol start pada aplikasi countdown timer untuk memulai menjalankan timer dan mengaktifkan lampu, dan tombol reset untuk mematikan lampu dan mengubah nilai timer menjadi nol.

\section{PENUTUP}

\section{Simpulan}

Berdasarkan hasil analisis, perancangan dan implementasi yang telah dilakukan, serta berdasarkan rumusan masalah yang ada, maka dapat diambil beberapa kesimpulan diantaranya sebagai berikut:

1. Pengendalian lampu tidak akan bekerja jika smartphone android diluar jarak jangkauan pancaran bluetooth yaitu jarak > 15 meter tanpa ada halangan, dan 12 meter ketika mendapat halangan; dan

2. Aplikasi yang dibuat dapat digunakan untuk mematikan dan menyalakan lampu melalui perintah button on/off, perintah suara, dan perintah countdown timer.

\section{Saran}

Dari hasil penelitian sistem ini tidak lepas dari kekurangan dan kelemahan. Oleh karena itu, penulis memberi saran yang dapat digunakan sebagai acuan dalam penelitian atau pengembangan selanjutnya, yaitu sebagai berikut:

1. Agar perangkat ini dapat digunakan dari jarak yang lebih jauh maka diperlukan alat penguat sinyal bluetooth;

2. Meng-offline-kan fitur perintah suara agar tidak tergantung dengan koneksi internet.

3. Hasil perancangan masih bisa dikembangkan seperti memperluas jarak kontrol yang tidak hanya dalam ruang lingkup lokal namun sudah bisa menggunakan Internet sebagai media Komunikasi dengan membuat sebuah website yang berfungsi sebagai jembatan data antara Android dan Arduino

\section{DAFTAR PUSTAKA}

B. Perkembangan and P. Pikir, "Pembuatan aplikasi," vol. 8, pp. 36-40, 2011.

B. S. Andika, "Kontrol Lampu Rumah Berbasis Android," pp. 1-11, 2015.

Dinda Tisi Calista, 2013. Modul

Bluetooth HC-05 Pada Adrduino.

https://dindatc.wordpress.com/2014/04/18/me ncoba-modul-bluetooth-hc-05- pada arduino. Diakses pada tanggal 21 april 2017

Elektronika Teknik . 2017. Pengertian Relay dan Fungsinya.

http://teknikelektronika.com/pengertian-relayfungsi-relay/. Diakses pada tanggal 25 april 2017

E. T. Setiawan, "Pengendalian lampu rumah berbasis mikrontroler arduino menggunakan smartphone android," TI-Atma STMIK Atma Luhur Pangkal pinang, pp. $1-8,2010$.

F. T. P. W and H. Priyatman, "Rancang bangun Kendali Lampu On/Off Dengan Smartphone Android Via Bluetooth,". Darwin Sudarma Pembimbing, pp. 1-5, 2013.

P. Rahmiati, G. Firdaus, and N. Fathorrahman, "Implementasi Sistem Bluetooth menggunakan Android dan Arduino untuk Kendali Peralatan Elektronik," J. ELKOMIKA Inst. Teknol. Nas. Bandung, 
vol. 2, no. 1, pp. 1-14, 2014.

Syahwil, Muhammad. 2013. Panduan Mudah Simulasi dan Praktek Mikrokontroler Arduino. Andi.

T. Akhir, P. Studi, D. T. Informatika, J. T. Elektro, and P. N. Manado, Aplikasi Android Menggunakan Media Bluetooth Berbasis Mikrokontroller. 2015.
V. W. Rumopa and D. Pembimbing, "Kontrol Penerangan Ruangan Menggunakan Sensor Suara (Speech Recognition) Berbasis Android Kontrol Penerangan Ruangan Menggunakan Sensor Suara (Speech Recognition) Berbasis Android," 2015. 